\title{
UNA SENTENCIA CONSTITUCIONAL EJEMPLAR DE JAVIER DELGADO BARRIO (Comentario a la STC 78/2010)
}

\author{
Joaquín Huelin Martínez de Velasco \\ Magistrado del Tribunal Supremo
}

\begin{abstract}
RESUMEN
El artículo analiza la relevancia de la STC 78/2010 en el marco de la doctrina constitucional sobre las relaciones entre el derecho a la tutela judicial y la decisión de los jueces ordinarios de no plantear una cuestión prejudicial ante el Tribunal de Justicia de la Unión Europea. En particular, pone de manifiesto su importancia en el desarrollo de esa construcción jurisprudencial y analiza los problemas derivados de la posterior evolución de esta última.
\end{abstract}

Palabras clave: cuestión prejudicial; derecho a la tutela judicial efectiva; Tribunal Constitucional; Tribunal de Justicia de la Unión Europea.

\begin{abstract}
This paper focuses on the Judgement of the Spanish Constitutional Court No $78 / 2010$, within the context of its case-law regarding the relationship between the right to effective judicial protection, on the one hand, and the refusal of ordinary judges to make a reference for a preliminary ruling of the Court of Justice. Specifically, it shows the relevance of this judgement as regards the mentioned case-law, and discusses the shortcomes of its subsequent developments.
\end{abstract}

Key words: preliminary ruling; right to effective judicial protection; Constitutional Court; Court of Justice of the European Union. 
I. INTROdUCCIÓN.-II. LAS SENTENCIAS 58/2004 y 194/2006.-III. LA SENTENCIA 78/2010.-IV. LAS SENTENCIAS 27/2013 y 212/2014.-V. REFLEXIÓN FINAL.VI. NOTA BIBLIOGRÁFICA.

\section{INTRODUCCIÓN}

Seguramente me equivoque, pero un liber amicorum* no es el escenario adecuado para hacer alarde de atributos doctrinales, de los que el autor de la contribución tal vez carezca, ni, creo yo, la ocasión oportuna para plasmar sesudas reflexiones científicas. Es un acto de celebración de una vida que, llegada a su cénit, inicia el jubileo.

Hace tiempo que Javier Delgado Barrio alcanzó el apogeo y allí permanece, en el culmen de su órbita. Su universo se encuentra jalonado de estrellas, muchas de ellas auténticos luceros que, con su brillo, iluminan la senda que otros hemos de transitar. En esa constelación despuntan algunos astros, supernovas que liberan gran cantidad de energía y que resisten a apagarse, irradiando una sorprendente luminosidad en un firmamento sembrado de oscuridad.

Una de esas luminarias es la STC 78/2010, de 20 de octubre, que arrojó luz en un espacio necesitado de claridad.

\section{LAS SENTENCIAS 58/2004 y 194/2006}

Según he indicado en alguna otra ocasión, tengo la impresión de que a nuestro Tribunal Constitucional le está costando encontrar su sitio en el entramado institucional de la Unión Europea. Durante muchos años ha dado la impresión de que la dimensión jurídica del proceso de integración en el Viejo Continente no fuera con él y este desencuentro ha tenido reflejo en su doctrina cuando se le ha pedido que, por el cauce del recurso de amparo, controle la decisión de un juez español de sentenciar un litigio sin dirigirse previamente al Tribunal de Justicia de la Unión Europea, pese a estar obligado a ello.

En sus primeros pronunciamientos sobre el particular entendió que esa forma de resolver carece de incidencia sobre el artículo 24 de

* Este trabajo se preparó como contribución al Libro Homenaje a Javier Delgado Barrio. Sin embargo, razones ajenas a su autor —un problema en la edición final del libro- impidieron que fuera incluido en él. Lo hace ahora en esta REVISTA con el mismo propósito de celebrar la trayectoria profesional de un jurista excepcional. 
la Constitución española. Negó dimensión constitucional al problema razonando que el reenvío prejudicial se regula en una norma del ordenamiento de la Unión Europea [hoy el artículo 267 del Tratado de Funcionamiento de la Unión Europea (TFUE)], que no es canon de constitucionalidad, por lo que no le incumbía garantizar su respeto, añadiendo, so pretexto de su similitud con la cuestión de inconstitucionalidad, que, como ocurre con esta última, la decisión de acudir al mecanismo prejudicial corresponde en exclusiva al órgano jurisdiccional que resuelve el litigio, de modo que su actuación no lesiona, en principio, garantía constitucional alguna (SSTC 111/1993, de 25 de marzo, FJ 2. ; 180/1993, de 31 de mayo, FJ 2. ${ }^{\circ}$; 201/1996, de 9 de diciembre, FJ 2. ${ }^{\circ}$; y 203/1996, de 9 de diciembre, FJ 2. ${ }^{\circ}$ ).

Sin embargo, el Tribunal Constitucional dio un golpe de timón y cambió de rumbo mediante la STC 58/2004, de 19 de abril, en la que juzgó que se vulnera el derecho a un proceso con todas las garantías si un órgano judicial (en aquel caso el Tribunal Superior de Justicia de Cataluña) resuelve un litigio obviando una ley (entonces autonómica) sobre la tasa fiscal del juego, por considerarla contraria al artículo 33 de la Sexta Directiva del IVA sin plantear cuestión prejudicial al Tribunal de Justicia. El caso era realmente límite, pues sobre la cuestión ya existía un pronunciamiento de los jueces de Luxemburgo (sentencia de 26 de junio de 1997, Careda y otros, asuntos acumulados C-370/95 a C-372/95), en el que señalaron los parámetros que se debían valorar para apreciar si un tributo interno se oponía a aquel precepto comunitario. Se daba, no obstante, la circunstancia de que el Tribunal Supremo y otros tribunales superiores de justicia, aplicando dichos parámetros, en resoluciones anteriores a la recurrida en amparo habían estimado que la tasa fiscal sobre el juego no contradecía la mencionada norma de la Sexta Directiva.

Pues bien, el contenido de esta sentencia del Tribunal Constitucional dejaba perplejo al lector, pues de su lectura no quedaba claro si la quiebra constitucional se produjo porque el Tribunal Superior de Justicia de Cataluña inaplicó la ley sin plantear la cuestión prejudicial, estando obligado a ello, o si tuvo lugar porque se apartó del entendimiento que otros órganos judiciales españoles habían alcanzado de la doctrina del Tribunal de Justicia en una sentencia anterior.

Las dudas fueron aclaradas en la sentencia 194/2006, de 19 de junio, que otorgó amparo al Gobierno de Canarias porque la Sala de lo Contencioso-Administrativo con sede en Las Palmas descartó, sin plantear cuestión prejudicial, el artículo 10.1.13 de la Ley 20/1991, relativa al impuesto general indirecto canario, donde se reproducía un precepto idéntico de la Ley 37/1992, del IVA, cuya oposición al Derecho co- 
munitario motivó que el Tribunal de Justicia resolviera (sentencia de 7 de mayo de 1998, Comisión/España, C-124/96) que nuestro país había incumplido sus compromisos con la Unión Europea. Anulada su sentencia por el Tribunal Constitucional, la Sala insular se dirigió al Tribunal de Justicia para interrogarle sobre los efectos de la citada sentencia Comisión/España en el referido precepto de la Ley 20/1991. En auto de 16 de abril de 2008 (Club Náutico de Gran Canaria, C-186/07), los jueces de Luxemburgo rechazaron contestar por no existir conexión comunitaria, ya que las Islas Canarias quedan fuera del ámbito de aplicación del sistema común del IVA.

La respuesta del Tribunal de Justicia evidencia que el Tribunal Constitucional podía muy bien haber otorgado el amparo sin introducirse en los vericuetos del Derecho comunitario, limitándose a afirmar que el Tribunal Superior de Justicia canario inaplicó una ley postconstitucional vigente sobre la que no incidía el ordenamiento jurídico de la Unión y sobre la que, por consiguiente, no ostentaba las facultades para desplazarla que, eventualmente, le confiere ese orden jurídico transnacional. Para decidir sobre la pretensión de amparo no sólo no hacía falta, sino que resultaba inconveniente el recorrido argumental seguido por el máximo intérprete de nuestra Constitución.

El análisis de estas dos sentencias del Tribunal Constitucional revela que en su ánimo estaba considerar que la decisión de un juez ordinario de soslayar por su propia autoridad una norma legal contraria al Derecho de la Unión infringe el artículo 24 de la Constitución, aun cuando no estuviera obligado a dirigirse a título prejudicial al Tribunal de Justicia, posición que casa mal con la jurisprudencia comunitaria y con los poderes que atribuye a los jueces nacionales para garantizar la efectividad del ordenamiento jurídico de la Unión.

Sabido es que el efecto directo de determinados productos normativos de dicho ordenamiento y su primacía permitieron al Tribunal de Justicia afirmar que los jueces nacionales están obligados a garantizar su plena eficacia, desplazando, si fuere menester, las disposiciones opuestas de la legislación interna con abstracción de su rango y sin necesidad de esperar a su derogación o a su anulación por cualquier procedimiento constitucional (sentencia de 9 de marco de 1978, Simmenthal, 106/77). Por consiguiente, han de aplicar, incluso de oficio, las normas de una Directiva que tengan efecto directo, no obstante la existencia de reglas internas que las contradigan (sentencia de 22 de junio de 1989, Fratelli Costanzo, 103/88).

Así pues, los jueces españoles tienen respecto de la ley interna contraria al Derecho de la Unión Europea unas facultades de las que ca- 
recen frente a la ley postconstitucional que se opone a la Carta Magna de 1978. En este último caso, antes de decidir el litigio deben dirigirse al Tribunal Constitucional para que expulse la previsión normativa que se opone a sus dictados (arts. 163 de la Constitución y 35.1 de la Ley Orgánica del Tribunal Constitucional) y, una vez producido el pronunciamiento, resolver en consecuencia. Por el contrario, si esa misma norma contradice las determinaciones del ordenamiento de la Unión queda constreñido a desplazarla, dejándola inaplicada, para otorgar toda su fuerza a la disposición del ordenamiento de la Unión con efecto directo sobre las relaciones jurídicas objeto del litigio.

Bien es verdad que esta potestad del juez interno queda acotada por el monopolio interpretativo del Tribunal de Justicia, a quien corresponde no sólo fijar la exégesis del Derecho de la Unión, sino también determinar cuáles de sus normas reúnen los requisitos para gozar de efecto directo. Así, la cuestión prejudicial resulta un trayecto de obligado tránsito para los jueces nacionales que resuelven en última instancia, salvo que concurran las estrictas condiciones requeridas por la doctrina Cilfit (sentencia de 6 de octubre de 1982, 283/81): que la cuestión del Derecho de la Unión suscitada no resulte pertinente para zanjar la contienda, que la disposición haya sido ya interpretada por el Tribunal de Justicia o que su correcta aplicación se imponga con una evidencia tal que no deje lugar a ninguna duda razonable, tanto al juez llamado a resolver el litigio como a los órganos jurisdiccionales de los demás Estados miembros y al propio Tribunal de Justicia.

La cuestión prejudicial resulta también de obligado planteamiento cuando afecta a la validez de una previsión de Derecho derivado de la Unión. Aquí opera otro poder exclusivo del Tribunal de Justicia, el de rechazo de las normas del ordenamiento de la Unión: si la disposición interna que ha de aplicar para resolver el litigio es transposición de otra del Derecho derivado de cuya oposición a los tratados sospecha, el juez nacional ha de dirigirse en todo caso y sin excepción, aun cuando su palabra no sea la última en el orden jurídico interno, al Tribunal de Luxemburgo para que resuelva, con carácter prejudicial, sobre la validez de aquella norma derivada (sentencia de 22 de octubre de 1987, Foto-Frost, 314/85).

Por todo ello, llama poderosamente la atención que el Tribunal Constitucional haya entendido que resulta infringido el artículo 24.1 de la Constitución como consecuencia de que un juez ordinario desplace y deje inaplicada una ley interna que se opone al ordenamiento de la Unión en los supuestos en los que no queda obligado a plantear la cuestión prejudicial. Esto es, cuando no está en juego la validez de una 
norma de Derecho derivado y, tratándose de una cuestión de interpretación, cuando no resuelve en última instancia o, siendo así, se dan las condiciones de la doctrina Cilfit. El Tribunal Constitucional parece desconocer que, actuando de tal manera, el juez ordinario no hace otra cosa que ejercer su potestad jurisdiccional, operando con normas jurídicas de distinto o igual rango y, en caso de conflicto, determinando la prevalente para aplicarla. En la colisión entre una disposición del legislador, estatal o autonómico, y una norma del Derecho de la Unión con efecto directo, el juez ordinario ha de postergar aquella primera porque esta última debe imponerse, operación que realiza con habitualidad cuando el conflicto se produce entre normas internas (superior e inferior; posterior y anterior; general y especial). No se trata, pues, de controlar el ejercicio de la potestad legislativa y desdecir a su titular, sino de comprobar la vigencia de sus productos mediante el juego interactivo de los distintos componentes del sistema de fuentes, tarea natural del juez ordinario.

\section{LA SENTENCIA 78/2010}

A la vista de los planteamientos que parecían ocultarse tras las SSTC 58/2004 y 194/2006, resultaba menester que el Tribunal Constitucional aclarara su doctrina. De no hacerlo, algún juez ordinario hubiera debido dirigirse al Tribunal de Justicia para preguntarle si es conforme con los principios jurisprudenciales decantados desde Luxemburgo una doctrina constitucional que considera repudiable la decisión de un órgano jurisdiccional de inaplicar una ley interna que estima contraria al Derecho de la Unión, dándose las condiciones Cilfit. La ocasión la brindó el recurso de amparo 8427-2006, en el que se suscitaba un supuesto de igual factura que el que dio lugar a la STC 194/2006.

Ese recurso fue resuelto en la STC 78/2010, de la que fue ponente Javier Delgado Barrio (las sentencias son una obra colectiva marcada por la impronta de su redactor). Superando el paralelismo que las anteriores sentencias establecían entre cuestión de inconstitucionalidad y cuestión prejudicial (FJ 2. ${ }^{\circ}$ ), este pronunciamiento fija pautas que iluminan la senda a seguir. Siendo el supuesto de hecho igual al de la STC 194/2006, concluye que el Derecho comunitario debía quedar al margen del debate, tanto por la materia (impuesto general indirecto canario) como por el lugar (Islas Canarias), por lo que no procedía plantearse si la inaplicación de la ley interna sin suscitar la cuestión preju- 
dicial vulneró el derecho a un proceso con todas las garantías (FF.JJ. 5. ${ }^{\circ}$ y $7 .^{\circ}$ ). La premisa de este razonamiento encubre la respuesta para el caso de que la situación hubiera pertenecido a los ámbitos propios del Derecho de la Unión, reconduciendo la posible vulneración a las situaciones en las que el desplazamiento de la norma interna se produce sin plantear la cuestión prejudicial allí donde resulta obligada. Si tal hubiera sido la tesitura, podría haber sido conculcado el mencionado derecho fundamental siempre y cuando se dieran las condiciones que exige la jurisprudencia para que una persona jurídico-pública, como el Gobierno de Canarias, pueda invocar en cuanto titular el mencionado derecho fundamental (FF.JJ. 6. ${ }^{\circ}$ y $7 .^{\circ}$ ).

Como se ve, la STC 78/2010 se apartó claramente de su precedente, la STC 194/2006, con la que comparte idéntico supuesto de hecho, llegando a resultados claramente distintos. Ofrece, además, pautas que autorizan a afirmar su condición de overruling respecto de la STC 58/ 2004, cuya doctrina aquilata, permitiendo atisbar que para los magistrados de Domenico Scarlatti el problema de constitucionalidad estriba en el hecho de que un juez ordinario inaplique una ley interna haciendo algo que no puede hacer y que pertenece — salvo excepcionesa otra instancia: interpretar por su propia autoridad las normas del ordenamiento de la Unión. La STC 78/2010 constituyó una auténtica supernova; sin embargo, como ocurre con la mayoría de estos productos estelares, su energía no nos iluminó por mucho tiempo.

\section{LAS SENTENCIAS 27/2013 y 212/2014}

La STC 27/2013, de 11 de febrero, parece volver al criterio anterior. Aborda un supuesto en el que la Sala Tercera del Tribunal Supremo, resolviendo en última instancia y estando, por ello, obligado a dirigirse a título prejudicial al Tribunal de Justicia, decidió no hacerlo porque, a su juicio, la exégesis de la norma del Derecho de la Unión que estaba llamado a aplicar resultaba clara. Se trataba, en síntesis, de saber si determinados requisitos señalados en la normativa comunitaria sobre la organización común de los mercados del lino y del cáñamo podían ser completados y adicionados por las regulaciones internas de los Estados miembros. El Tribunal Supremo no albergaba duda de que sí podían y, por ello, resultaba aplicable para decidir el litigio una orden de la Junta de Extremadura aprobada al efecto, tesis que la sociedad recurrente no compartía y en cuyo planteamiento dicha orden debió ser preterida para zanjar la contienda, aplicándose directa y exclusiva- 
mente la regulación comunitaria. El Tribunal Constitucional denegó el amparo porque la falta de planteamiento de la cuestión prejudicial no condujo a la inaplicación de norma interna alguna (FJ 7. ${ }^{\circ}$, in fine).

Este razonamiento "desenmascara» al Tribunal Constitucional y pone en evidencia que para él la vulneración de la garantía fundamental no se produce porque el juez resuelva un litigio en el que está implicado el Derecho de la Unión actuando manifiestamente al margen del mismo o sin seguir los cauces interpretativos o de aplicación de insoslayable cumplimiento, sino porque al actuar así deja inaplicada una norma interna. Conclusión preocupante, porque parece volver a la doctrina que la STC 78/2010 había superado, dejando sobre la mesa la duda sobre cuál hubiera sido su respuesta ante la decisión de un tribunal ordinario de descartar una ley interna contraria al Derecho de la Unión dándose las condiciones Cilfit y no resultando, por ello, menester plantear la cuestión prejudicial.

Comparto los razonamientos del voto particular de la magistrada Adela Asua a la STC 27/2013. Considera que resultaba aplicable al caso la solución adoptada en las sentencias 58/2004 y 78/2010, pues el Tribunal Supremo alcanzó por su propia, autónoma y exclusiva convicción la conclusión sobre la forma correcta de interpretar el Derecho de la Unión, sin aportar elementos externos y objetivos de contraste o de apoyo de esa convicción que acreditasen que la misma evidencia sería compartida por los órganos jurisdiccionales de los otros Estados miembros y por el Tribunal de Justicia. Esto es, sin justificar que no quedaba obligado a plantear la cuestión prejudicial de interpretación.

Por su parte, la STC 212/2014, de 18 de diciembre, insiste en una línea semejante, también con la discrepancia de la magistrada Asua Batarrita. Considera que la impugnada en amparo decisión del Tribunal Superior de Justicia de Andalucía (Sala de lo Contencioso-Administrativo con sede en Sevilla), que resolvía en apelación y, por ende, como órgano de última instancia, de no dirigirse a título prejudicial al Tribunal de Justicia aparece suficiente motivada desde la perspectiva del artículo 24.1 de la Constitución (FJ $4 .^{\circ}$ ) y niega que haya vulnerado el derecho a un proceso con todas las garantías del artículo 24.2, ya que explicó por qué no albergaba dudas sobre la conformidad de la decisión administrativa controlada (resolución de un concurso para la adjudicación de puestos de trabajo en el sector público, sin valorar el tiempo en que se prestaron servicios interinamente) con la Directiva 1999/70/CE del Consejo, de 28 de junio de 1999, relativa al Acuerdo Marco sobre el trabajo de duración determinada, según ha sido interpretada por la sentencia de 8 de septiembre de 2011, Rosado Santana (C-177/10). Para 
el Tribunal Constitucional, resulta decisivo que no «conste que dicho órgano hubiera tenido dudas sobre la necesidad de plantear cuestión prejudicial sobre ese aspecto» (FJ 5. ${ }^{\circ}$ ).

El Tribunal Constitucional vuelve, en mi opinión, a no apreciar cabalmente la posición del juez nacional que resuelve en última instancia ante la interpretación del Derecho de la Unión Europea necesaria para decidir el litigio. En los términos de la doctrina Cilfit, para que decaiga la obligación de plantear cuestión prejudicial que incumbe al juez que se encuentra en esa tesitura no basta con que no tenga dudas sobre la correcta interpretación y aplicación de la norma comunitaria, sino que también resulta menester que tenga claro que tampoco las albergan los demás órganos jurisdiccionales de la Unión, incluido el Tribunal de Justicia. Según he indicado en alguna otra ocasión, no se trata tanto de una convicción subjetiva del juez como de una condición objetiva de la norma. Hubiera sido necesario, pues, que el juez ordinario explicitara la claridad de la disposición del Derecho de la Unión, según había sido ya interpretada por el Tribunal de Justicia en la sentencia Rosado Santana, cuya intervención anterior, al ser otra de las situaciones en las que con arreglo a la sentencia Cilfit decae la obligación del juez nacional que resuelve en última instancia de suscitar la cuestión prejudicial, pudiera haber dado cobertura a la Sala de lo Contencioso-Administrativo de Andalucía para eludir la formulación del reenvío. Pero no lo hizo así, limitándose, según parece deducirse del texto de la sentencia del Tribunal Constitucional, a expresar que tenía claro cómo debía interpretarse la Directiva.

En realidad, el Tribunal Superior de Justicia no plasmó las razones que le autorizaban a eludir su obligación de entablar el diálogo prejudicial con el Tribunal de Justicia de la Unión Europea.

\section{REFLEXIÓN FINAL}

Y es en esa encrucijada donde debe centrarse el debate. La incógnita que hay que despejar es la siguiente: $\dot{c}$ acarrea alguna consecuencia jurídica en el círculo de los intereses jurídicamente protegibles del titular de la acción procesal la decisión de un juez nacional de resolver el litigio sin plantear una cuestión prejudicial, de interpretación o de validez, cuando está obligado a hacerlo?

En una situación tal, bien el juez incumplidor resuelve mediante una selección inadecuada de la norma aplicable, violentando el sistema de fuentes, bien se decide el pleito, en uno de sus aspectos (el de la interpretación del Derecho de la Unión y el del control de su validez), por un 
órgano jurisdiccional distinto del señalado por el legislador. Estas disfunciones pueden llegar a incidir sobre las garantías fundamentales que están en juego en la aplicación del Derecho de la Unión, cuyo contenido mínimo es el que se le otorga en los convenios internacionales sobre tutela de los derechos humanos y en los ordenamientos constitucionales nacionales, pues el catálogo de los derechos fundamentales de la Unión es emanación de unos y otros, en cuanto tradición común a los Estados miembros. Así se obtiene del preámbulo de la Carta de los Derechos Fundamentales de la Unión y del artículo 6 del Tratado de la Unión Europea (TUE), que, además, reconoce a aquélla el mismo valor jurídico que a los tratados.

Pues bien, la doctrina del Tribunal Constitucional permite afirmar que se vulnera el derecho a obtener la tutela judicial efectiva, proclamado en el artículo 24.1 de la Constitución española y garantizado por el artículo 47 de la Carta en el ámbito del ordenamiento de la Unión, en el que se dispone la obligación de los Estados miembros de regular las vías de recurso necesarias a tal fin (art. 19.1 TUE), cuando la resolución del litigio se adopta mediante una selección arbitraria o manifiestamente irrazonable de la norma aplicable, cuando se decide incurriendo en un error patente y, en fin, cuando el juez adopta su decisión desvinculándose del sistema de fuentes establecido.

Si se produce una selección arbitraria de la norma aplicable y se resuelve, por ello, al margen del sistema de fuentes, la doctrina del Tribunal Constitucional permite hablar de falta de motivación porque la norma considerada es manifiestamente inaplicable. Es verdad que las nociones de «razonabilidad», de «arbitrariedad» y de «error patente» tienen contornos difusos, de modo que su delimitación introduce un cierto grado de subjetivismo en el control, corriéndose el riesgo de que, por este cauce, el Tribunal Constitucional se introduzca en terrenos que le están vedados.

Pero no lo es menos que, tratándose de la aplicación del Derecho de la Unión Europea, ese riesgo de subjetivismo se diluye por la interposición de un instrumento de control normativo dispuesto por el ordenamiento, de talante objetivo: la cuestión prejudicial. En otros términos, si el juez interno resuelve un litigio seleccionando, de manera arbitraria o irrazonable o errando de forma patente, una norma que manifiestamente no es aplicable al caso es porque previamente ha incumplido su obligación de acudir al Tribunal de Justicia pidiéndole su intervención e, inmiscuyéndose allí donde no debía, ha interpretado por su propia autoridad aquel ordenamiento jurídico, depurándolo, en su caso, también de forma indebida. 
Por consiguiente, si, estando obligado, un juez interno no acude a título prejudicial al Tribunal de Justicia, cabe que zanje el litigio aplicando una norma distinta de la que correspondía. En esta tesitura no habrá seguido los controles normativos previstos por el ordenamiento, desvinculándose del sistema de fuentes. Resulta muy difícil negar con toda rotundidad que en un escenario tal el derecho a la tutela judicial efectiva queda siempre indemne.

Resulta razonable preguntarse también si, en esas situaciones, puede quedar afectado el derecho al proceso debido (art. 24.2 de la Constitución), en la medida en que al no plantearse la cuestión prejudicial, debiendo hacerlo, se viola una de las garantías que lo conforman.

Sabido es que corresponde al juez ordinario la selección de la norma aplicable para resolver el litigio, pero si esa selección pasa por soslayar una norma legal por su contradicción con el Derecho comunitario se hace ineludible la promoción de la correspondiente cuestión prejudicial, salvo que se den las condiciones de la doctrina Cilfit. Si no tiene lugar, si, una vez seleccionada la ley que rige el litigio, el juez la evita so pretexto de su oposición al Derecho comunitario sin antes interrogar al Tribunal de Justicia, a quien corresponde fijar la interpretación de este último o controlar su validez, desconocerá una de las garantías que integran el proceso debido, pudiendo colocar al interesado en una situación de efectiva indefensión.

Parece, en suma, que no hay que hacer grandes violencias conceptuales para, en determinados supuestos, vincular con los derechos a la tutela judicial efectiva y a un proceso público con todas las garantías la renuencia de un juez a dirigirse al Tribunal de Justicia de la Unión Europea e interrogarle a título prejudicial sobre la interpretación y la validez del Derecho comunitario, si estando obligado a ello esa actitud le lleva a resolver al margen del sistema de fuentes y de los controles normativos previstos en el ordenamiento para garantizar su exclusivo sometimiento a las leyes, con el resultado de negar al justiciable los derechos que le reconoce aquel ordenamiento jurídico. Los mimbres se encuentran en la jurisprudencia comunitaria y en la constitucional.

Por ello, conviene retomar la senda señalada por el Tribunal Constitucional en la STC 78/2010 e indagar con mayor detenimiento y profundidad en las vías argumentales que ofrece, máxime si se tiene presente que el panorama ha cambiado desde el Tratado de Lisboa, debido al reconocimiento en el artículo 47 de la Carta del derecho fundamental a la tutela judicial efectiva en los ámbitos cubiertos por el ordenamiento jurídico de la Unión y al establecimiento de la obligación de los 
Estados miembros, ex artículo 19.1 TUE, de disponer las vías de recursos necesarias para garantizar esa tutela.

La STC 78/2010 no debe caer en saco roto ni podemos permitirnos el lujo de desdeñar las pautas que ofrece, con la batuta de Javier Delgado Barrio, sin cuyo magisterio el que firma estas líneas nunca las habría podido escribir, no hubiera sido capaz.

\section{Nota BIBLIOGRÁficA}

La bibliografía sobre las implicaciones para el derecho a la tutela judicial efectiva de la negativa del juez español a plantear una cuestión prejudicial ante el Tribunal de Justicia es muy amplia. Sin ánimo exhaustivo, cabe recordar el trabajo de R. Alonso García y J. M. BAÑo LEÓN, «El recurso de amparo frente a la negativa a plantear cuestión prejudicial ante el Tribunal de Justicia de la Comunidad Europea», Revista Española de Derecho Constitucional, núm. 29, 1990, págs. 193 a 222. Más madrugador aún, I. BorRajo INIESTA, «El juez español y el derecho comunitario", Actualidad Administrativa, núm. 25, 1986, págs. 1417 a 1424, se interrogó sobre las relaciones entre la cuestión prejudicial y el control judicial de las leyes.

El propio R. Alonso García, El juez español y el derecho comunitario, Tirant lo Blanch, Valencia, 2003, que fue galardonado con la XVI edición del Premio «Martínez Emperador» del Consejo General del Poder Judicial, reflexionó sobre la cooperación a través del reenvío prejudicial, sus implicaciones con el artículo 24 de la Constitución, analizando el papel que le corresponde al Tribunal Constitucional y su condición de «órgano jurisdiccional» a efectos prejudiciales. Y, más recientemente, con la última jurisprudencia del Tribunal Constitucional a la vista, ha insistido en Cuestión prejudicial europea y tutela judicial efectiva (a propósito de las SSTC 58/2004, 194/2006 y 170/2010), Instituto de Derecho Europeo e Integración Regional, Madrid, 2011. J. M. BAÑo LEÓN incidió de nuevo en el problema: «El Tribunal Constitucional, juez comunitario: amparo frente al no planteamiento de cuestión prejudicial», Revista de Derecho Comunitario Europeo, núm. 18, 2004, págs. 465 a 481 .

Entre los trabajos que han visto la luz a raíz de la STC 58/2004, cabe destacar el análisis de P. MARTín RodRíguEz, «La cuestión prejudicial como garantía constitucional: a vueltas con la relevancia constitucional del Derecho de la Unión (A propósito de la STC 58/2004, de 19 de abril, asunto tasa fiscal sobre el juego)», Revista Española de De- 
recho Constitucional, núm. 72, 2004, págs. 315 a 346. También el de J. I. Ugartemendía EcEIZABarRena, «El recurso a la prejudicial (234 TCE) como cuestión de amparo (A propósito de la STC 58/2004, de 19 de abril de 2004, que otorga el amparo frente a una vulneración del art. $24 \mathrm{CE}$ originada por incumplimiento de la obligación de plantear la cuestión prejudicial comunitaria)», Revista Española de Derecho Europeo, núm. 11, 2004, págs. 441 a 474.

Resulta muy recomendable el análisis de C. IzouiERdo SANS, «Cuestión prejudicial y artículo 24 de la Constitución Española», Revista General de Derecho Europeo, núm. 23, 2011.

El autor de esta contribución reflexionó, bajo un título inusual para un texto jurídico, sobre las consecuencias de la doctrina sentada en las SSTC 58/2004 y 194/2006, animando al Tribunal Constitucional a cambiar de rumbo en el recurso de amparo en el que, después, sería dictada la STC 78/2010: J. Huelin MarTíneZ DE Velasco, «Kafka se pasea por Domenico Scarlatti», Derecho y Jueces, núm. 51, 2009, págs. 3-4. Completé las reflexiones en J. Huelin MarTínez DE Velasco, «Las implicaciones constitucionales del incumplimiento del deber de plantear cuestión prejudicial ante el Tribunal de Justicia de la Unión Europea (una aproximación "post-Lisboa”)», Revista Española de Derecho Europeo, núm. 39, 2011, págs. 375 a 412. 
